\title{
Investigation of Streptococcus salivarius- mediated inhibition of pneumococcal adherence to pharyngeal epithelial cells
}

\author{
Jayne Manning 1,3, Eileen M. Dunne', Philip A. Wescombe4, John D. F. Hale ${ }^{4}$, E. Kim Mulholland 1,5, John R. Tagg ${ }^{4,6}$,
} Roy M. Robins-Browne $e^{2,3}$ and Catherine Satzke $e^{1,3,7^{*}}$

\begin{abstract}
Background: Pneumococcal adherence to the nasopharyngeal epithelium is a critical step in colonisation and disease. The probiotic bacterium, Streptococcus salivarius, can inhibit pneumococcal adherence to epithelial cells in vitro. We investigated the mechanism(s) of inhibition using a human pharyngeal epithelial cell line (Detroit 562) following pre-administration of two different strains of $S$. salivarius.

Results: Whilst the bacteriocin-encoding megaplasmids of S. salivarius strains $\mathrm{K} 12$ and M18 were essential to prevent pneumococcal growth on solid media, they were not required to inhibit pneumococcal adherence. Experiments testing S. salivarius K12 and two pneumococcal isolates (serotypes 19F and 6A) showed that inhibition of 19F may involve S. salivarius-mediated blocking of pneumococcal binding sites: a negative correlation was observed between adherence of K12 and 19F, and no inhibition occurred when K12 was prevented from contacting epithelial cells. K12-mediated inhibition of adherence by $6 \mathrm{~A}$ may involve additional mechanisms, since no correlation was observed between adherence of $\mathrm{K} 12$ and $6 \mathrm{~A}$, and $\mathrm{K} 12$ could inhibit $6 \mathrm{~A}$ adherence in the absence of cell contact.

Conclusions: These results suggest that $S$. salivarius employs several mechanisms, including blocking pneumococcal binding sites, to reduce pneumococcal adherence to pharyngeal epithelial cells. These findings extend our understanding of how probiotics may inhibit pneumococcal adherence and could assist with the development of novel strategies to prevent pneumococcal colonisation in the future.
\end{abstract}

Keywords: Probiotics, Probiotic mechanisms, Respiratory tract, Streptococcus salivarius, Streptococcus pneumoniae, Pneumococcus, Colonisation, Adherence

\section{Background}

Streptococcus pneumoniae (the pneumococcus) commonly colonises the nasopharynx of healthy humans, especially young children. Carriage is considered a prerequisite for pneumococcal disease and facilitates the transmission of pneumococci throughout communities [1]. Dissemination of pneumococci from the nasopharynx to other body sites can give rise to diseases such as meningitis, sepsis,

\footnotetext{
* Correspondence: catherine.satzke@mcri.edu.au

'Pneumococcal Research, Murdoch Childrens Research Institute, The Royal Children's Hospital, Parkville, VIC, Australia

${ }^{3}$ Department of Microbiology and Immunology at the Peter Doherty Institute for Infection and Immunity, The University of Melbourne, Parkville, VIC, Australia

Full list of author information is available at the end of the article
}

pneumonia, and otitis media. An estimated 800,000 children under the age of five die from pneumococcal infections each year, with most deaths occurring in low-income countries where carriage rates are especially high [2]. Strategies targeting the reduction of pneumococcal colonisation could potentially reduce this burden of disease.

Current pneumococcal conjugate vaccines (PCVs) induce protection against $10-13$ of the most common diseasecausing serotypes via the induction of anti-capsular antibodies. Although PCVs have successfully reduced carriage and disease caused by vaccine serotypes, they are expensive to produce and have led to an increase in colonisation by non-vaccine serotypes (serotype replacement) [3]. In recent years, there has been increased interest in the use of

\section{) Biomed Central}


probiotics, which are defined as live microorganisms that can confer a health benefit to the host, to reduce pathogen colonisation and respiratory tract infections [4]. Proposed mechanisms of probiotic action include inhibition of pathogen colonisation via competition for binding, direct inhibition due to the activity of secreted antimicrobial molecules and the induction of immunomodulatory effects in the host [5-9].

Streptococcus salivarius is a member of the respiratory tract microbiota and has been commercially available as an oral probiotic for more than a decade [10]. Small clinical trials have shown that administration of S. salivarius strains $\mathrm{K} 12$ and M18 can reduce the occurrence of tonsillitis and otitis media [11] and reduce dental plaque levels in children [12], as well as treat halitosis in adults [13]. Several in vitro studies have found that $S$. salivarius can prevent the growth of a range of respiratory pathogens, including the pneumococcus, through production of megaplasmid-encoded bacteriocins and bacteriocin-like inhibitory substances (BLIS) [7, 14-16]. However, the mechanisms by which they inhibit pathogen adherence in vivo are unknown. We have previously shown that S. salivarius K12 can inhibit pneumococcal adherence to a human epithelial cell line (CCL-23) [17]. Here, we demonstrate that the same phenomenon is observed in Detroit 562 pharyngeal epithelial cells and investigate the inhibitory mechanisms involved, including the role of the S. salivarius megaplasmid. Our results suggest that S. salivarius K12 inhibits pneumococcal adherence by blocking pneumococcal binding sites, although other mechanisms such as direct interference through the action of secreted molecules may also contribute.

\section{Methods}

\section{Bacterial strains, cell lines and culture conditions}

Bacterial isolates are described in Tables 1 and 2. Pneumococcal isolates were selected to represent a range of

Table 1 Streptococcus salivarius isolates used in this study

\begin{tabular}{ll}
\hline S. salivarius isolate & Known bacteriocins \\
\hline K12 & SalA, SalB \\
K12 ${ }^{\text {mp- }}$ & - \\
M18 & SalA, Sal9, SalM \\
M18 ${ }^{\text {mp- }}$ & - \\
A234 & SalA \\
NR & SalB \\
T18A & SalA, SalB \\
T30A & Unknown \\
Min5 & SalA, SalB \\
20P3 & SalA \\
\hline
\end{tabular}

SalA: salivaricin A [36]; SalB: salivaricin B [23]; Sal9: salivaricin 9 [37]; SalM: salivaricin $M$ [24]; $m p$ : megaplasmid
Table 2 Pneumococcal isolates used in this study

\begin{tabular}{|c|c|c|}
\hline Pneumococcal isolate & Serotype & Origin \\
\hline PMP1081 & 1 & Australia \\
\hline PMP278 & 3 & Fiji \\
\hline PMP241 & 4 & South Africa \\
\hline PMP812 & 5 & Bangladesh \\
\hline PMP6 (ATCC $\left.{ }^{\oplus} 6305^{\mathrm{TM}}\right)$ & 5 & Germany \\
\hline PMP1043 & $6 \mathrm{~A}$ & USA \\
\hline PMP17 & $6 \mathrm{~A}$ & Fiji \\
\hline PMP434 & $6 \mathrm{~B}$ & Fiji \\
\hline PMP437 & $6 C$ & Fiji \\
\hline PMP1086 & $7 F$ & Australia \\
\hline PMP296 & $9 \mathrm{~V}$ & Fiji \\
\hline PMP130 & 14 & Fiji \\
\hline PMP222 & $18 \mathrm{C}$ & South Africa \\
\hline PMP843 & $19 F$ & USA \\
\hline PMP292 & $19 \mathrm{~A}$ & Fiji \\
\hline PMP283 & $22 \mathrm{~F}$ & Unknown \\
\hline
\end{tabular}

serotypes and based on their ability to adhere to human epithelial cells. S. salivarius isolates were sourced from Blis Technologies Ltd, New Zealand. All isolates were cultured at $37{ }^{\circ} \mathrm{C}$ in $5 \% \mathrm{CO}_{2}$ on horse blood agar (HBA; Thermo Fisher Scientific) plates, in Todd-Hewitt broth (THB; Oxoid), or THB supplemented with $0.5 \%(\mathrm{w} / \mathrm{v})$ yeast extract (THY; Becton Dickinson). Deferred antagonism testing was carried out on BaCa (Columbia agar base; Life Technologies Ltd.) plates supplemented with human blood $(5 \%, \mathrm{v} / \mathrm{v})$ and $\mathrm{CaCO}_{3}(0.1 \%, \mathrm{w} / \mathrm{v})$ except where noted.

The Detroit 562 pharyngeal epithelial carcinoma cell line (ATCC CCL-138) was maintained in RPMI 1640 (Sigma-Aldrich) supplemented with $10 \%$ (v/v) foetal bovine serum (FBS, Thermo Fisher Scientific). Monolayers were released by incubation with $0.25 \%$ trypsin/EDTA (0.25\% (w/v) trypsin, $0.1 \mathrm{mM}$ EDTA, Life Technologies) for $10 \mathrm{~min}$ at $37{ }^{\circ} \mathrm{C}$ in $5 \% \mathrm{CO}_{2}$ and seeded into 24-well trays at a concentration of $1.5 \times 10^{5}$ cells/well in RPMI supplemented with $5 \%$ FBS for use in adherence assays.

\section{Deferred antagonism testing}

Testing for deferred antagonism was performed as described previously [18]. Briefly, overnight THB cultures of $S$. salivarius (producer strain) were used to inoculate a $1-\mathrm{cm}$-wide line down the middle of a human blood agar plate (as described above). Plates were incubated for $18 \mathrm{~h}$ at $37{ }^{\circ} \mathrm{C}$ in $5 \% \mathrm{CO}_{2}$, S. salivarius growth was removed, and the plate inverted over a chloroformsoaked cloth for $30 \mathrm{~min}$ to kill any remaining bacteria. Residual chloroform was then evaporated by exposure of the agar surface to air for $30 \mathrm{~min}$. Overnight THB cultures of pneumococcal indicator strains were then streaked at 
right angles to the previously grown $S$. salivarius and incubated for a further 12-16 h. Plates were examined for growth where $S$. salivarius had previously grown, and prevention of pneumococcal growth recorded as + (observed) or - (not observed).

\section{Adherence assays}

Adherence assays were performed as described previously [17] with several modifications. D562 cells seeded into 24-well trays were washed twice with Hanks buffered salt solution (HBSS; Gibco ${ }^{\circ}$, Life Technologies) before the addition of $500 \mu \mathrm{l} /$ well RPMI without serum. Bacteria were grown to log phase in THY (S. salivarius: $1.5 \mathrm{~h}$, pneumococci: $3 \mathrm{~h}$ ) and resuspended in $0.85 \%(\mathrm{w} / \mathrm{v})$ $\mathrm{NaCl}$ (Merck) to $\sim 1.5 \times 10^{9} \mathrm{CFU} / \mathrm{ml}$. A 10-fold dilution series of S. salivarius was prepared in $0.85 \% \mathrm{NaCl}$ and $10 \mu \mathrm{l}$ aliquots of high $\left(\sim 1.5 \times 10^{7} \mathrm{CFU} /\right.$ well $)$, medium $\left(\sim 1.5 \times 10^{6} \mathrm{CFU} /\right.$ well $)$, and low $\left(\sim 1.5 \times 10^{5} \mathrm{CFU} /\right.$ well $)$ concentrations of bacteria were administered to duplicate wells before centrifugation at $114 \times g$ for $3 \mathrm{~min}$ to promote bacterial adherence to the cell monolayer. Plates were incubated at $37{ }^{\circ} \mathrm{C}$ in $5 \% \mathrm{CO}_{2}$ for $1 \mathrm{~h}$. Pneumococci were prepared as above and added to all wells at a concentration of $\sim 1.5 \times 10^{6} \mathrm{CFU} /$ well (MOI of 10 pneumococci: 1 D562 cell) $1 \mathrm{~h}$ after $S$. salivarius. Centrifugation was performed as above and plates were incubated for a further $1 \mathrm{~h}$. Cells (and adherent bacteria) were then washed three times with HBSS and harvested after the addition of $200 \mu \mathrm{l} 0.25 \%$ trypsin/EDTA to each well, incubation for $10 \mathrm{~min}$ at $37^{\circ} \mathrm{C}$ in $5 \% \mathrm{CO}_{2}$, and addition of $800 \mu \mathrm{l}$ of THY to each well with mechanical disruption. Lysates were stored at $-20{ }^{\circ} \mathrm{C}$ until tested. Pneumococcal adherence (genome copies/ well) was determined by quantitative real-time PCR (qPCR) targeting lytA (see below). The effect of bacterial infection on D562 cells was monitored microscopically and no significant cytopathic effects were observed during the adherence assay conditions. The effect of $S$. salivarius on pneumococcal adherence was calculated by normalising all treatments against wells containing pneumococci alone. The ability of the pneumococcal isolates to invade cells was measured by incubating cells with media containing $10 \mu \mathrm{g} / \mathrm{ml}$ penicillin and $200 \mu \mathrm{g} / \mathrm{ml}$ gentamicin for $15 \mathrm{~min}$ after incubation with pneumococci for $1 \mathrm{~h}$ (Additional file 1 ), confirming the validity of this model to investigate adherence. The adherence of $S$. salivarius to D562 cells at the time of pneumococcal administration was calculated following incubation of $\sim 1.5 \times 10^{6} \mathrm{CFU} /$ well bacteria for $1 \mathrm{~h}$ at $37{ }^{\circ} \mathrm{C}$ in $5 \% \mathrm{CO}_{2}$. Cells were washed three times with HBSS to remove non-adherent bacteria and harvested as above. CFU/well was determined by viable count on HBA plates and expressed as mean $\%$ adherence \pm standard deviation compared to the inoculum added.

We performed preliminary experiments to determine whether heparin, which can inhibit pneumococcal adherence to epithelial cells in vitro by competitively binding to glycosylaminoglycans [19], could also inhibit S. salivarius adherence to D562 cells. Cells were incubated with $100 \mathrm{U} /$ well of heparin (Pfizer) for $1 \mathrm{~h}$ before the addition of $S$. salivarius as above and results expressed as \% adherence compared to $S$. salivarius without heparin. S. salivarius adherence to D562 cells over time was measured by qPCR targeting dex (see below).

We also investigated whether non-adherent $S$. salivarius had an effect on pneumococcal adherence. To do this, adherence assays were performed as described above, except that wells were washed three times with HBSS to remove unbound S. salivarius and fresh medium was added after S. salivarius pre-administration and before the addition of pneumococci. To determine the inhibitory effect of $S$. salivarius in the absence of cell contact, $S$. salivarius was preadministered to D562 cells via permeable transwell inserts with a pore size of $0.4 \mu \mathrm{m}$ (Corning, In vitro Technologies). To further investigate the mechanisms involved in the inhibition of pneumococcal adherence, preparations of K12 were: a) heat-killed by incubating at $70{ }^{\circ} \mathrm{C}$ for $30 \mathrm{~min}$ with their lack of viability confirmed by the absence of growth on HBA; b) enzymatically treated to remove outer surface proteins and carbohydrates of S. salivarius K12 by (i) resuspending $\mathrm{K} 12$ inocula in a final concentration of $5 \mathrm{mg} / \mathrm{ml}$ pronase E [20], or (ii) by the addition of $5 \mu \mathrm{l}$ of $1 \mathrm{mg} / \mathrm{ml}$ sodium periodate [21] to $\mathrm{K} 12$ inocula prepared in $0.85 \% \mathrm{NaCl}$ for $15 \mathrm{~min}$ at $37{ }^{\circ} \mathrm{C}$ in $5 \% \mathrm{CO}_{2}$, and c) reducing $\mathrm{K} 12$ protein synthesis by resuspending $\mathrm{K} 12$ inocula in $2 \mathrm{mg} / \mathrm{ml}$ spectinomycin and incubating for $30 \mathrm{~min}$ at $37{ }^{\circ} \mathrm{C}$ in $5 \% \mathrm{CO}_{2}$. Following all treatments, $\mathrm{K} 12$ inocula were washed twice in $0.85 \% \mathrm{NaCl}$ prior to use in adherence assays.

\section{qPCR}

DNA extraction and pneumococcal qPCR assays were performed as described previously [17]. Primers (Sigma Aldrich) and dual-labelled probes (Eurogentec) were designed to detect chromosomal (dextranase gene, dex) and megaplasmid (mp) target sequences in S. salivarius. Primer/probe sequences and final concentrations were as follows: dexF2: TGAAGCAGATAACTTGGTGGTG (300 $\mathrm{nM})$; dexR2: CTCTCTGCTGGCACAGCTT (300 nM); dex probe2: HEX-AGAAGTAGGTCCATCATCTGCC-3' BHQ-1 (75 nM); mpF: AAGCCTTGTGCATCGACTCT (200nM); mpR: AACCAAGACGCGACTGTTGA (200 $\mathrm{nM})$; mp probe: FAM-TGACCCTTTTTGTTGGTCGT3'-BHQ-1 (300 nM). Specificity of both assays was confirmed by sequencing the amplified product and testing against a panel of closely related streptococcal species (Additional file 2: Table S1). qPCR reactions were carried out in duplicate using Agilent Brilliant III master mix (Agilent Technologies, Integrated Sciences), containing $1 \mu \mathrm{l}$ of template DNA in $25 \mu \mathrm{l}$ final volume using a Stratagene 
Mx3005P qPCR machine (Agilent Technologies). The cycling conditions were: $1 \times 3 \mathrm{~min}$ at $95^{\circ} \mathrm{C}, 40 \times 20 \mathrm{~s}$ at $95^{\circ} \mathrm{C}$ followed by $20 \mathrm{~s}$ at $60{ }^{\circ} \mathrm{C}$. Pneumococcal and S. salivarius DNA was quantified using standard curves of reference strain isolates (ATCC 6305 and K12, respectively) and bacterial loads were calculated as described previously [22], based on $1 \mathrm{pg}$ of genomic DNA being equivalent to 447.4 pneumococcal cells and $422.1 \mathrm{~S}$. salivarius cells (assuming one genome per cell, and one copy of the target gene per genome).

\section{Statistical analysis}

Data were analysed using Prism 6.0d (GraphPad Software, Inc.) and Excel (Microsoft). Student's t-test was used to compare pneumococcal adherence in all treatment groups. Spearman's rank test was used to correlate pneumococcal and S. salivarius K12 adherence in adherence assays. A $p$ value of $<0.05$ was considered statistically significant for all assays. For all experiments $n \geq 3$ unless otherwise stated.

\section{Results}

\section{S. salivarius reduces pneumococcal adherence to} pharyngeal epithelial cells

Previous studies in our laboratory demonstrated that $S$. salivarius $\mathrm{K} 12$ inhibits pneumococcal adherence to CCL-23 human epithelial cells in vitro, with the strongest effect seen when K12 was added before pneumococci (pre-administration). In this study, we investigated the mechanisms underlying this inhibition using a cell line more relevant to the pneumococcal ecological niche of the nasopharynx, Detroit 562 human pharyngeal epithelial cells (D562), and two isolates representing serotypes that commonly colonise (6A [PMP1043] and 19F [PMP843]). Pneumococcal adherence was measured following pre-administration of commercial probiotic S. salivarius strains K12 or M18 at high, medium and low doses.
All doses of K12 significantly inhibited $6 \mathrm{~A}$ and $19 \mathrm{~F}$ adherence $(p<0.001$, Fig. 1$)$. All doses of M18 inhibited 6A adherence (high: $p<0.001$, medium: $p<0.001$, low: $p=0.023$, Fig. 1a), but only the high dose inhibited 19F adherence $(p<0.001$, Fig. $1 \mathrm{~b})$. K12 adherence to D562 cells was higher than that of M18 $(532.3 \pm 86.49 \%$ vs. $12.5 \pm$ $8.14 \%, p<0.001)$. Heparin, which is known to inhibit pneumococcal adherence to epithelial cells by competing for binding to cell surface glycosylaminoglycans [19], did not affect $S$. salivarius $\mathrm{K} 12$ adherence to D562 cells $(115.8 \pm 27.81 \%, p=0.380$, Student's $t$-test).

K12 adherence showed significant negative correlation with $19 \mathrm{~F}$ adherence but not with $6 \mathrm{~A}$ adherence (19F: $r=-0.68, p=0.002$; 6A: $r=-0.12, p=0.66$; Fig. 2 ). Significant inhibition of pneumococcal adherence was also observed following removal of non-adherent K12 by washing prior to the addition of pneumococci (Direct + wash, Table 3: all doses $p<0.001$ ).

\section{The K12 megaplasmid is essential to prevent} pneumococcal growth but not adherence

The megaplasmids of S. salivarius K12 and M18 encode bacteriocins that prevent the growth of a range of bacterial species on solid media $[14,16,23,24]$, but their roles in inhibition of pneumococcal growth or adherence are unknown. We compared the ability of K12, M18, their megaplasmid-negative derivatives, and a panel of S. salivarius strains to inhibit the growth of 15 pneumococcal isolates by deferred antagonism. S. salivarius strains K12, M18, A234, NR, T18A and Min5 inhibited all of the pneumococcal isolates tested (Table 4). Neither megaplasmid-negative strain $\left(\mathrm{K} 12^{\mathrm{mp}-}\right.$ or $\left.\mathrm{M} 18^{\mathrm{mp}-}\right)$ or strain $\mathrm{T} 30 \mathrm{~A}$ prevented the growth of any of the pneumococcal isolates tested (Table 4).

Since the S. salivarius megaplasmids were essential to prevent the growth of pneumococci, and K12 caused a greater reduction in pneumococcal adherence than M18 (Fig. 1), we next compared the ability of $\mathrm{K} 12$ and $\mathrm{K} 12$ mpstrains to inhibit pneumococcal adherence to D562 cells. Although the exact copy number of the megaplasmid is
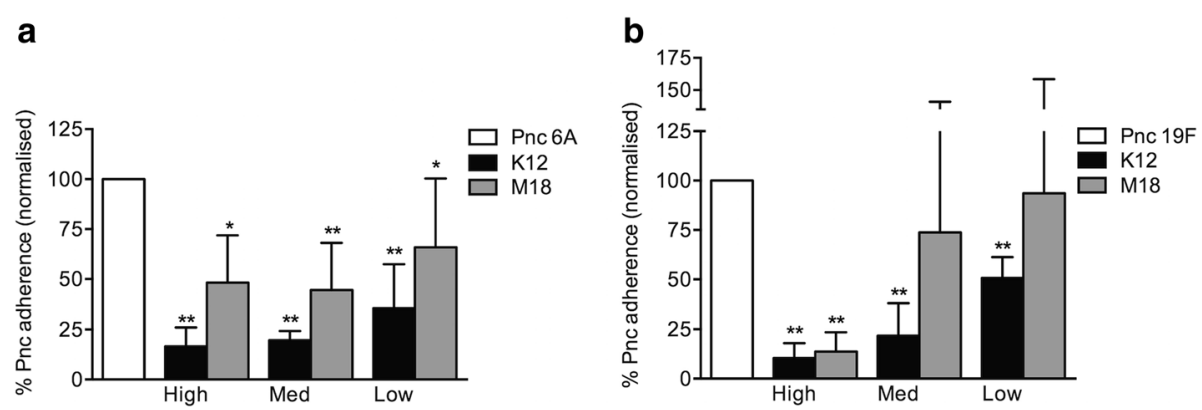

Fig. 1 Pneumococcal adherence of serotypes $6 \mathrm{~A}(\mathbf{a})$ and $19 \mathrm{~F}$ (b) to pharyngeal epithelial cells following pre-administration of S. salivarius. Approximately $1.4 \times 10^{6}$ CFU pneumococci were added to D562 monolayers at an MOI of 11:1. Pneumococcal adherence was determined when incubated with pneumococci alone (Pnc, normalised to $100 \%$ ), or pre-incubated for $1 \mathrm{~h}$ with S. salivarius K12 or M18 at high $\left(\sim 1.6 \times 10^{7} \mathrm{CFU}\right)$, medium $\left(\sim 1.6 \times 10^{6} \mathrm{CFU}\right)$, or low $\left(\sim 1.6 \times 10^{5} \mathrm{CFU}\right)$ doses. Data are mean $+\mathrm{SD} ; n \geq 3$. * indicates $p<0.05$, ${ }^{* *}$ indicates $p<0.001$ when compared to Pnc alone (Student's t-test) 

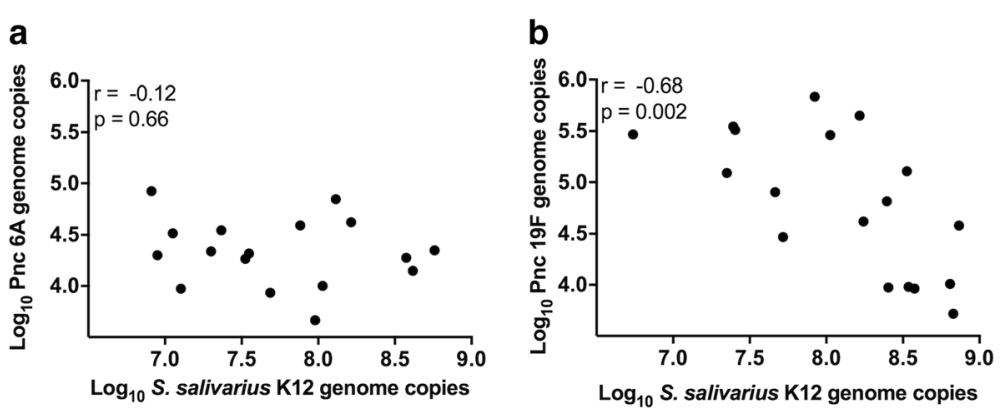

Fig. 2 Correlation of adherence of S. salivarius K12 and pneumococcal serotype 6A (a) and 19F (b) adherence to pharyngeal epithelial cells. Adherence of S. salivarius and pneumococci to D562 monolayers was determined following pre-incubation for $1 \mathrm{~h}$ with high $\left(\sim 1.6 \times 10^{7} \mathrm{CFU}\right)$, medium $\left(\sim 1.6 \times 10^{6} \mathrm{CFU}\right)$, or low $\left(\sim 1.6 \times 10^{5} \mathrm{CFU}\right)$ doses of $\mathrm{S}$. salivarius $\mathrm{K} 12$ and subsequent incubation with $\sim 1.4 \times 10^{6}$ CFU pneumococci for 1 h. $r=$ Spearman rank correlation coefficient

unknown, preliminary qPCR analysis confirmed that the ratio of K12 chromosomal DNA to megaplasmid DNA remained stable during bacterial growth $(1.43, n=1)$ and throughout assay conditions (1.17 and 1.20 after 1 and $2 \mathrm{~h}$ incubation with D562 monolayer, respectively, $n=1$ ). All doses of $\mathrm{K}_{12} \mathrm{mp}^{-}$significantly inhibited 6A adherence (high: $p<0.001$, medium: $p<0.001$, low: $p=0.016$, Fig. 3a). When compared to K12, there was some evidence that the $\mathrm{K} 12^{\mathrm{mp}-}$ strain resulted in less inhibition than the K12 strain, but this difference was only statistically significant at the high dose $(p=0.044$, Fig. 3a). For the 19F strain, only the high and medium doses of $\mathrm{K}_{12} \mathrm{mp}^{-}$significantly inhibited pneumococcal adherence. We found no differences in the ability of $\mathrm{K} 12$ and $\mathrm{K} 12^{\mathrm{mp}-}$ to adhere to D562 cells $(532 \pm 86.49 \%$ vs. $511 \pm 6.92 \%, p=0.695)$ or in their adherence to D562 cells over time (Fig. 4, $p>0.05$ for all time points).

\section{Cell contact is required for $\mathrm{K} 12$ to inhibit adherence by serotype $19 \mathrm{~F}$, but not serotype $6 \mathrm{~A}$}

To determine whether contact of S. salivarius with D562 cells was required to inhibit pneumococcal adherence, we performed adherence assays in which K12 was administered using transwell inserts, preventing direct contact with epithelial cells but allowing the passage of secreted molecules. Using this transwell system, no inhibition of $19 \mathrm{~F}$ adherence was observed at any dose, while $6 \mathrm{~A}$ adherence was inhibited at the medium $(p=0.049)$ and low $(p<0.001)$ doses (Table 3$)$. Preliminary experiments showed that culture supernatants did not inhibit pneumococcal growth in the deferred antagonism test.

\section{Protein synthesis may be required for $\mathrm{K} 12$ to inhibit $6 \mathrm{~A}$ adherence}

The above experiments indicated the involvement of multiple mechanisms for S. salivarius inhibiting pneumococcal adherence. We further investigated the molecular mechanism(s) of $S$. salivarius $\mathrm{K} 12$ inhibition of $6 \mathrm{~A}$ adherence by performing different treatments on the K12 inoculum prior to its use in adherence assays. Denaturing proteins and killing K12 cells (heat-treatment), interrupting protein synthesis (spectinomycin treatment), and removing outer surface carbohydrates (sodium periodate treatment) and proteins (pronase E treatment) all reduced inhibition of 6A adherence compared with untreated K12 (Fig. 5). However, only

Table 3 Pneumococcal adherence to pharyngeal epithelial cells following pre-administration of S. salivarius K12 by various methods

\begin{tabular}{|c|c|c|c|c|c|c|c|}
\hline \multirow[b]{3}{*}{ Pneumococcal serotype } & \multirow[b]{3}{*}{ K12 Dose ${ }^{c}$} & \multicolumn{6}{|c|}{ Pneumococcal adherence $^{a}$} \\
\hline & & \multicolumn{2}{|l|}{ Direct } & \multicolumn{2}{|l|}{ Transwell } & \multicolumn{2}{|l|}{ Direct + wash } \\
\hline & & $\%(95 \% \mathrm{Cl})$ & $p$ value $^{b}$ & $\%(95 \% \mathrm{Cl})$ & $p$ value $^{b}$ & $\%(95 \% \mathrm{Cl})$ & $p$ value $^{b}$ \\
\hline \multirow[t]{3}{*}{$6 \mathrm{~A}$} & High & $16.6(6.8,26.5)$ & $<0.001$ & $90.5(23.9,157.1)$ & 0.698 & $25(12.5,37.4)$ & $<0.001$ \\
\hline & Medium & $19.6(14.7,24.4)$ & $<0.001$ & $61.5(18.4,104.5)$ & 0.049 & $45.2(21.9,68.5)$ & $<0.001$ \\
\hline & Low & $35.4(12.3,58.5)$ & $<0.001$ & $44.1(22.8,65.5)$ & $<0.001$ & $45.1(29.1,61.1)$ & $<0.001$ \\
\hline \multirow[t]{3}{*}{$19 F$} & High & $10.4(2.5,18.4)$ & $<0.001$ & $84.7(33.6,135.7)$ & 0.338 & $41.8(17.6,66.4)$ & $<0.001$ \\
\hline & Medium & $21.8(1.7,41.8)$ & $<0.001$ & $121.3(16.5,226.2)$ & 0.581 & $31.4(13.2,49.6)$ & $<0.001$ \\
\hline & Low & $50.7(33.8,67.5)$ & $<0.001$ & $102.2(33.7,170.5)$ & 0.933 & $45.3(16.7,74.0)$ & $<0.001$ \\
\hline
\end{tabular}

${ }^{\mathrm{a} D i r e c t: ~ p r e-a d m i n i s t r a t i o n ~ o f ~ K 12 ~ d i r e c t l y ~ o n t o ~ D 562 ~ m o n o l a y e r ; ~ T r a n s w e l l s: ~ p r e-a d m i n i s t r a t i o n ~ o f ~ K 12 ~ v i a ~ t r a n s w e l l ~ i n s e r t s ; ~ D i r e c t ~+~ w a s h: ~ p r e-a d m i n i s t r a t i o n ~ o f ~}$ K12 directly onto D562 monolayers followed by a washing step to remove non-adherent K12

${ }^{\mathrm{b}} p$ values calculated from pneumococcal adherence alone compared to pneumococcal adherence following different methods of K12 pre-administration (Student's t test, $\left.{ }^{*} p<0.05\right)$

'High: $1.5 \times 10^{7} \mathrm{CFU} / \mathrm{ml}$; Medium: $1.5 \times 10^{6} \mathrm{CFU} / \mathrm{ml}$ and Low: $\sim 1.5 \times 10^{5} \mathrm{CFU} / \mathrm{ml}$ 
Table 4 Deferred antagonism of S. salivarius strains against a panel of pneumococcal isolates

\begin{tabular}{|c|c|c|c|c|c|c|c|c|c|c|c|}
\hline \multirow[b]{2}{*}{ Pneumococcal test strain } & \multirow[b]{2}{*}{ Serotype } & \multicolumn{10}{|c|}{ S. salivarius producer strain } \\
\hline & & $\mathrm{K} 12$ & $\mathrm{~K} 12^{\mathrm{mp}-}$ & M18 & $\mathrm{M} 18^{\mathrm{mp}-}$ & A234 & NR & $\mathrm{T} 18 \mathrm{~A}$ & $\mathrm{~T} 30 \mathrm{~A}$ & Min5 & $20 \mathrm{P3}$ \\
\hline PMP1081 & 1 & + & - & + & - & + & + & + & - & + & + \\
\hline PMP278 & 3 & + & - & + & - & + & + & + & - & + & + \\
\hline PMP241 & 4 & + & - & + & - & + & + & + & - & + & - \\
\hline PMP812 & 5 & + & - & + & - & + & + & + & - & + & + \\
\hline PMP1043 & $6 \mathrm{~A}$ & + & - & + & - & + & + & + & - & + & - \\
\hline PMP17 & $6 \mathrm{~A}$ & + & - & + & - & + & + & + & - & + & + \\
\hline PMP434 & $6 B$ & + & - & + & - & + & + & + & - & + & + \\
\hline PMP437 & $6 C$ & + & - & + & - & + & + & + & - & + & + \\
\hline PMP1086 & $7 F$ & + & - & + & - & + & + & + & - & + & + \\
\hline PMP296 & $9 \mathrm{~V}$ & + & - & + & - & + & + & + & - & + & + \\
\hline PMP130 & 14 & + & - & + & - & + & + & + & - & + & - \\
\hline PMP222 & $18 \mathrm{C}$ & + & - & + & - & + & + & + & - & + & + \\
\hline PMP292 & $19 A$ & + & - & + & - & + & + & + & - & + & - \\
\hline PMP843 ${ }^{\mathrm{a}}$ & $19 F$ & + & - & + & - & NT & NT & NT & NT & NT & NT \\
\hline PMP283 & $22 \mathrm{~F}$ & + & - & + & - & + & + & + & - & + & + \\
\hline
\end{tabular}

" + " indicates inhibition of pneumococcal growth and " - " indicates no inhibition, $n=2$

NT not tested

aperformed on horse blood agar plates

spectinomycin-treated K12 could no longer significantly inhibit $6 \mathrm{~A}$ adherence $(p=0.402$, Fig. 5).

\section{Discussion}

In this study, we found that various bacteriocin-producing strains of $S$. salivarius can prevent pneumococcal growth on solid media and that the commercial probiotic strains, K12 and M18, inhibit pneumococcal 6A and 19F adherence to a pharyngeal epithelial cell line. Studies investigating the probiotic mechanisms of $S$. salivarius have largely focused on the role of bacteriocins and BLIS. The $\sim 190 \mathrm{~kb}$ megaplasmid of $S$. salivarius K12 harbours genes encoding the bacteriocins salivaricin A2 and B, which prevent the growth of some bacterial pathogens, including Streptococcus pyogenes, in vitro $[7,14,15]$. Our results showed that the K12 megaplasmid is required to prevent pneumococcal growth in vitro, but is not essential to inhibit pneumococcal adherence. Therefore the primary mechanism of inhibition of pneumococcal adherence in this model does not appear to be mediated by megaplasmid-encoded bacteriocins; although we note that lack of inhibition of $19 \mathrm{~F}$ adherence by a low dose of $\mathrm{K}_{1} 2^{\mathrm{mp}-}$ indicates a possible role for the megaplasmid at this concentration. Instead, our findings indicated that $S$. salivarius $\mathrm{K} 12$ can inhibit pneumococcal adherence by blocking pneumococcal binding sites on D562 cells. We observed a correlation between S. salivarius K12 adherence to D562 cells and inhibition of adherence by pneumococcal isolate PMP843 (19F). We also found that
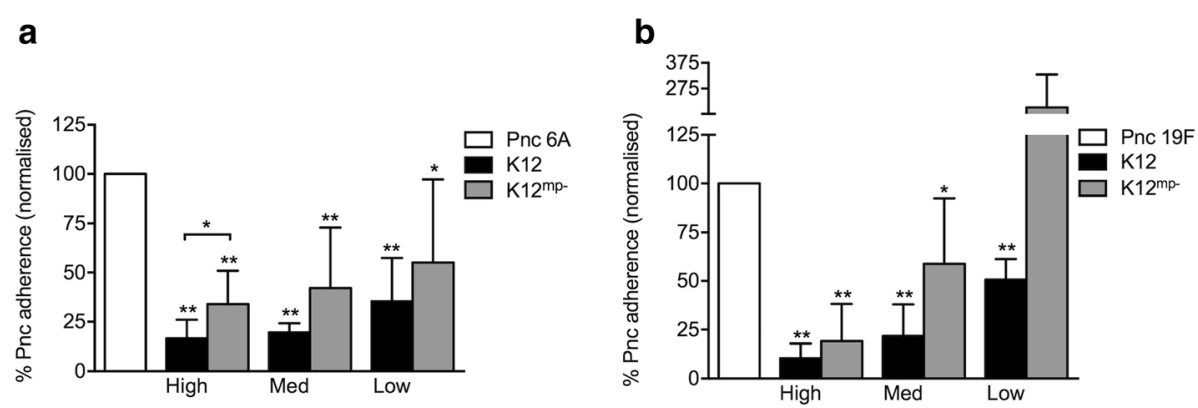

Fig. 3 Adherence of pneumococcal serotypes $6 \mathrm{~A}(\mathbf{a})$ and $19 \mathrm{~F}(\mathbf{b})$ to pharyngeal epithelial cells following pre-administration of megaplasmid positive (K12) and negative (K12 ${ }^{\mathrm{mp}-}$ ) S. salivarius K12 strains. Approximately $1.5 \times 10^{6}$ CFU pneumococci were added to D562 monolayers at an MOl of 10:1. Pneumococcal adherence was determined when incubated with pneumococci alone (Pnc, normalised to $100 \%$ ), or pre-incubated for $1 \mathrm{~h}$ with S. salivarius $\mathrm{K} 12$ or S. salivarius K12 $2^{\mathrm{mp}-}$ at high $\left(\sim 2 \times 10^{7} \mathrm{CFU}\right)$; medium $\left(\sim 2 \times 10^{6} \mathrm{CFU}\right.$, med); or low $\left(\sim 2 \times 10^{5} \mathrm{CFU}\right)$ doses. Data are mean + SD; $n \geq$ 6. ${ }^{*}$ indicates $p<0.05,{ }^{* *}$ indicates $p<0.001$ when compared to Pnc alone (Student's $t$ test) 


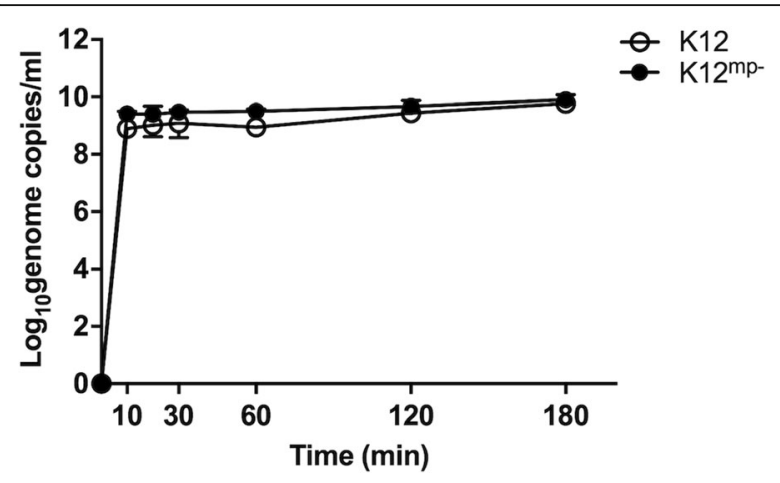

Fig. 4 Time course of S. salivarius adherence to D562 cells. Cells were inoculated with either $\sim 1.1 \times 10^{5}$ CFU of S. salivarius K12 or $\sim 1.9 \times$ $10^{5} \mathrm{CFU}$ of S. salivarius $\mathrm{K} 12^{\mathrm{mp}-}$ and the number of adherent bacteria measured over three hours. Median $\pm \mathrm{IQR}$ for both $S$. salivarius isolates are depicted $(n \geq 2)$

K12 contact with cells was essential for this inhibition. K12 binding to D562 cells did not require megaplasmidencoded molecules, since a megaplasmid-negative strain of K12 displayed equal adherence. We observed differences in the inhibition of pneumococcal adherence depending on both the strain of $S$. salivarius used and the pneumococcal isolate tested. This was not unexpected, given that S. salivarius strains vary in their capacity to adhere to epithelial cells and inhibit other pathogens $[7,15,16]$. The pneumococcus is a diverse pathogen, with different strains and serotypes known to behave differently in vitro and in vivo $[25,26]$. Overall, S. salivarius K12 displayed stronger inhibition of pneumococcal adherence than the M18 strain, possibly due to its increased capacity to adhere to D562 cells. Interestingly, K12 adherence to D562 cells did not correlate with $6 \mathrm{~A}$ adherence, suggesting that mechanisms other than S. salivarius-mediated blocking of pneumococcal binding sites on epithelial cells may be involved in the inhibition of

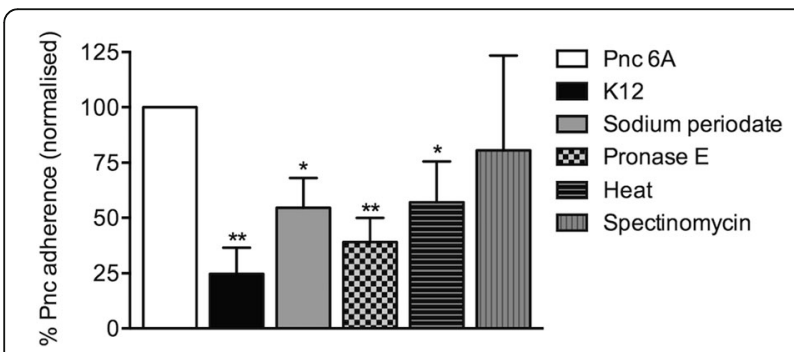

Fig. 5 Adherence of pneumococcal serotype 6A to pharyngeal epithelial cells following pre-administration of treated S. salivarius K12. Approximately $1.5 \times 10^{6}$ CFU pneumococci were added to D562 monolayers at an MOI of 10:1. Pneumococcal adherence was determined when incubated with pneumococci alone (Pnc, normalised to $100 \%$ ), or pre-incubated for $1 \mathrm{~h}$ with approximately $1.5 \times 10^{7}$ CFU S. salivarius K12 (untreated), or treated with sodium periodate, Pronase $\mathrm{E}$, heat-killed (heat), or spectinomycin. Data are mean $+\mathrm{SD} ; n \geq 3$. * indicates $p<0.05,{ }^{* *}$ indicates $p<0.001$ when compared to Pnc alone (Student's t test)
6A adherence. This was further supported by the inhibition of $6 \mathrm{~A}$ adherence by all doses of M18 despite its low adherence capability. Although a high dose of megaplasmidnegative K12 could still inhibit 6A adherence, the effect was significantly less than that observed with megaplasmidpositive $\mathrm{K} 12$, indicating a possible contribution to inhibition by the K12 megaplasmid in this assay. Transwell experiments demonstrated that for $19 \mathrm{~F}$, contact of S. salivarius K12 with D562 cells was required to inhibit pneumococcal adherence, consistent with a previous report showing that contact with epithelial cells was needed for S. salivarius K12 to inhibit adherence by S. pyogenes to HEp-2 cells [27]. However, low doses of K12 administered in the absence of cell contact could inhibit adherence of $6 \mathrm{~A}$. This could be due to bacteriocins or other secreted products, which may not necessarily be encoded on the megaplasmid. The differences observed using varying doses of probiotic suggest that quorum sensing may play a role in the expression of S. salivarius genes relevant to pneumococcal inhibition.

Further transwell experiments that test the K12 megaplasmid-negative strain may determine whether the molecules involved are chromosomally or plasmid encoded. Preliminary attempts to detect if bacteriocins were secreted through transwell membranes by deferred antagonism were unsuccessful, however this approach may have been insufficiently sensitive.

Overall, the data obtained in this study suggest that the primary mechanism by which $S$. salivarius $\mathrm{K} 12$ inhibits pneumococcal adherence to D562 cells is by blocking pneumococcal attachment to the epithelial cell surface. A number of pneumococcal surface molecules have been shown to play a role in adherence, such as the adhesion molecule PsaA, which binds to cell surface carbohydrates [28]. For S. salivarius, various cell surface molecules including fibrils and fimbriae have been implicated in adherence [29]. As heparin does not block $S$. salivarius adherence to D562 cells, glycosylaminoglycans do not seem to be a shared cell surface receptor. Since airway epithelial cells derived from carcinomas, such as D562 cells, can display altered expression of surface molecules compared to primary human epithelial cells [30], further investigation of common receptors used by these species should include testing of primary cells. Although inhibition of pneumococcal adherence could be due to competition for receptor-mediated binding, it could also result through a less specific mechanism, such as steric hindrance, or the ability of S. salivarius to mask pneumococcal binding sites. Other potential mechanisms by which $S$. salivarius may inhibit pneumococcal adherence, such as immune modulation of epithelial cells [31], were not examined in this study. Additionally, the in vitro model lacks the complexity of the nasopharynx, which can harbour a wide range of colonising bacterial species that interact with each other and with epithelial cells. 
Whilst megaplasmid-encoded bacteriocins are required to inhibit the growth of pneumococci on solid media, our data suggest that it is the adherence of $S$. salivarius to epithelial cells that primarily blocks pneumococcal adherence in vitro. Therefore, strategies to use $S$. salivarius as a probiotic in the respiratory tract should optimise the ability of this species to colonise the target tissue. In vitro studies performed in our laboratory, and by others, have shown that the addition of probiotic bacteria to epithelial cells prior to pathogen administration is more effective than attempting to disrupt established pathogen colonisation $[17,27]$. In clinical studies, high doses of M18 achieve greater colonisation rates and density in the oral cavity compared to lower doses [15]. Clinical studies of $S$. salivarius $\mathrm{K} 12$ as an oral probiotic have involved daily administration of high doses of the bacterium in an effort to achieve long-term colonisation of the oral cavity [32-34]. S. salivarius may be better suited as a probiotic for the oral cavity, where it predominates, than for the nasopharynx, the preferred niche of the pneumococcus. Strategies that facilitate S. salivarius adherence to the nasopharyngeal epithelium, such as the nasal spray recently employed by Santagati and colleagues [35], would likely be needed for this probiotic to inhibit pneumococcal colonisation in vivo.

\section{Conclusions}

Bacteriocin-encoding megaplasmids of $S$. salivarius strains K12 and M18 were essential to prevent pneumococcal growth on solid media but were not required to inhibit pneumococcal adherence to pharyngeal epithelial cells. Our results suggest that $S$. salivarius K12 employs several mechanisms, including blocking pneumococcal binding sites, to reduce pneumococcal adherence to pharyngeal epithelial cells. Further research is needed to identify the specific molecules involved. These findings contribute to our understanding of how probiotics may inhibit pneumococcal adherence and could assist with the development of novel strategies to prevent pneumococcal colonisation in the future.

\section{Additional files}

Additional file 1: Supporting Information S1. Raw data used to generate figures and tables. (XLSX $52 \mathrm{~kb}$ )

Additional file 2: Table S1. Specificity of dex and $m p$ gene targets to detect Streptococcus salivarius. DNA was extracted from pure cultures grown on HBA agar and $0.1 \mathrm{ng}$ DNA of each isolate listed was used as a template for the dex and $m p$ qPCR reactions, as described in the methods section. Mean Ct from duplicate wells is shown. (DOCX $15 \mathrm{~kb}$ )

\section{Abbreviations}

ATCC: American type culture collection; BLIS: Bacteriocin-Like Inhibitory Substance; CFU: Colony forming unit; DNA: deoxyribonucleic acid; EDTA: Ethylenediaminetetraacetic acid; FBS: Foetal bovine serum; HBA: Horse blood agar; HBSS: Hanks buffered salt solution; MOI: Multiplicity of infection;
PCR: Polymerase chain reaction; THB: Todd Hewitt broth; THY: Todd Hewitt broth supplemented with yeast extract

\section{Acknowledgements}

We thank Casey Pell, Monica Nation, Jenna Smyth and Laura Boelsen for expert technical assistance, and Dr Paul Licciardi for critical review of the manuscript. For the provision of isolates we thank A/Prof Fiona Russell and the Fiji pneumococcal project team; Prof Kate O'Brien, Johns Hopkins Bloomberg School of Public Health; Prof Susan Hollingshead, University of Birmingham; Prof Samir Saha and the staff of the Child Health Research Foundation, Dhaka Shishu Hospital, Prof Shabir Madhi, University of Witwatersand and A/Prof Jorge Vidal, Rollins School of Public Health, Emory University.

\section{Funding}

This study was funded by the Murdoch Childrens Research Institute and the Victorian Government's Operational Infrastructure Support program. Blis Technologies provided the S. salivarius isolates. JM is supported by an Australian Postgraduate Award, Australian Government. CS is supported by a Career Development Fellowship, National Health and Medical Research Council, Australia. The funders had no role in the study design, data collection and analysis, decision to publish, or preparation of the manuscript.

Availability of data and materials

All data generated or analysed during this study are included in this published article and its supplementary information files.

\section{Authors' contributions}

All authors contributed to conception and design of the study and critical revision of the manuscript. JM performed deferred antagonism testing and adherence assays. JM, PAW and JDFH analysed and interpreted deferred antagonism results. JM, EMD and CS analysed and interpreted adherence assay results. JM, EMD and CS drafted the manuscript. All authors read and approved the final manuscript

\section{Competing interests}

JDF $\mathrm{H}$ is a current employee, PAW is a former employee and JRT is an advisor of the company Blis Technologies Ltd. This does not alter the authors' adherence to the Good Publication Practice guidelines for pharmaceutical companies (GPP3)

\section{Consent for publication}

Not applicable.

Ethics approval and consent to participate

Not applicable.

\section{Author details}

${ }^{1}$ Pneumococcal Research, Murdoch Childrens Research Institute, The Royal Children's Hospital, Parkville, VIC, Australia. ${ }^{2}$ Infectious Diseases and Microbiology, Murdoch Childrens Research Institute, The Royal Children's Hospital, Parkville, VIC, Australia. ${ }^{3}$ Department of Microbiology and Immunology at the Peter Doherty Institute for Infection and Immunity, The University of Melbourne, Parkville, VIC, Australia. ${ }^{4}$ Blis Technologies Ltd, Dunedin, New Zealand. ${ }^{5}$ London School of Hygiene and Tropical Medicine, London, UK. ${ }^{6}$ Department of Microbiology and Immunology, University of Otago, Dunedin, New Zealand. ${ }^{7}$ Department of Paediatrics, The University of Melbourne, Parkville, VIC, Australia.

Received: 4 February 2016 Accepted: 20 September 2016 Published online: 29 September 2016

\section{References}

1. Simell B, Auranen K, Kayhty H, Goldblatt D, Dagan R, O'Brien KL, et al. The fundamental link between pneumococcal carriage and disease. Expert Rev Vaccines. 2012;11:841-55.

2. O'Brien KL, Wolfson LJ, Watt JP, Henkle E, Deloria-Knoll M, McCall N, et al. Burden of disease caused by Streptococcus pneumoniae in children younger than 5 years: global estimates. Lancet. 2009;374:893-902.

3. Weinberger DM, Malley $\mathrm{R}$, Lipsitch $M$. Serotype replacement in disease after pneumococcal vaccination. Lancet. 2011;378:1962-73. 
4. Licciardi PV, Toh QZ, Dunne EM, Wong SS, Mulholland EK, Tang M, et al. Protecting against Pneumococcal Disease: Critical Interactions between Probiotics and the Airway Microbiome. PLoS Pathog. 2012. doi:10.1371/ journal.ppat.1002652

5. Prince T, McBain AJ, O'Neill CA. Lactobacillus reuteri protects epidermal keratinocytes from Staphylococcus aureus-induced cell death by competitive exclusion. Appl Environ Microbiol. 2012;78:5119-26.

6. Fukuda S, Toh H, Hase K, Oshima K, Nakanishi Y, Yoshimura K, et al. Bifidobacteria can protect from enteropathogenic infection through production of acetate. Nature. 2011;469:543-7.

7. Santagati M, Scillato M, Patane F, Aiello C, Stefani S. Bacteriocin-producing oral streptococci and inhibition of respiratory pathogens. FEMS Immunol Med Microbiol. 2012:65:31.

8. Cosseau C, Devine DA, Dullaghan E, Gardy JL, Chikatamarla A, Gellatly S, et al. The commensal Streptococcus salivarius K12 downregulates the innate immune responses of human epithelial cells and promotes host-microbe homeostasis. Infect Immun. 2008;76:4163-75.

9. Park MK, Vu N, Kwon YM, Lee Y-T, Yoo S, Cho YH, et al. Lactobacillus plantarum DK119 as a probiotic confers protection against Influenza virus by modulating innate immunity. PLoS One. 2013. doi:10.1371/journal.pone.0075368.

10. Wescombe PA, Hale JD, Heng NC, Tagg JR. Developing oral probiotics from Streptococcus salivarius. Future Microbiol. 2012;7:1355-71.

11. Di Pierro F, Donato G, Fomia F, Adami T, Careddu D, Cassandro C, et al. Preliminary pediatric clinical evaluation of the oral probiotic Streptococcus salivarius K12 in preventing recurrent pharyngitis and/or tonsillitis caused by Streptococcus pyogenes and recurrent acute otitis media. Int J Gen Med. 2012;5:991-7.

12. Burton JP, Drummond BK, Chilcott CN, Tagg JR, Thomson WM, Hale JD, et al. Influence of the probiotic Streptococcus salivarius strain M18 on indices of dental health in children: a randomized double-blind, placebo-controlled trial. J Med Microbiol. 2013;62:875-84.

13. Burton JP, Moore CJ, Speiser G, Tagg JR. A preliminary study of the effect of probiotic Streptococcus salivarius K12 on oral malodour parameters. J Appl Microbiol. 2006;100:754-64.

14. Wescombe PA, Burton JP, Cadieux PA, Klesse NA, Hyink O, Heng NCK, et al. Megaplasmids encode differing combinations of lantibiotics in Streptococcus salivarius. Anton Leeuw Int J G. 2006;90:269-80.

15. Burton JP, Wescombe PA, Macklaim JM, Chai MHC, MacDonald K, Hale JDF, et al. Persistence of the oral probiotic Streptococcus salivarius M18 is dose dependent and megaplasmid transfer can augment their bacteriocin production and adhesion characteristics. PLoS One. 2013. doi:10.1371/ journal.pone.0065991.

16. Patras KA, Wescombe PA, Roesler B, Hale JD, Tagg JR, Doran KS. Streptococcus salivarius K12 Limits Group B Streptococcus Vaginal Colonization. Infect Immun. 2015;83:3438-44.

17. Dunne EM, Toh ZQ, John M, Manning J, Satzke C, Licciardi PV. Investigating the effects of probiotics on pneumococcal colonization using an in vitro adherence assay. J Vis Exp. 2014. doi:10.3791/51069.

18. Tagg JR, Bannister LV. Fingerprinting beta-hemolytic streptococci by their production of and sensitivity to bacteriocine-like inhibitors. J Med Microbiol. 1979:12:397-411.

19. Tonnaer EL, Hafmans TG, Van Kuppevelt TH, Sanders EA, Verweij PE, Curfs $\mathrm{JH}$. Involvement of glycosaminoglycans in the attachment of pneumococci to nasopharyngeal epithelial cells. Microbes Infect. 2006;8:316-22.

20. Botes M, Loos B, van Reenen CA, Dicks LMT. Adhesion of the probiotic strains Enterococcus mundtii ST4SA and Lactobacillus plantarum 423 to Caco-2 cells under conditions simulating the intestinal tract, and in the presence of antibiotics and anti-inflammatory medicaments. Arch Microbiol. 2008;190:573-84.

21. Rennemeier C, Hammerschmidt S, Niemann S, Inamura S, Zaehringer U, Kehrel BE. Thrombospondin-1 promotes cellular adherence of Gram-positive pathogens via recognition of peptidoglycan. FASEB J. 2007;21:3118-32.

22. Smith-Vaughn H, Byan R, Nadkarni M, Jacques NA, Halpin S, et al. Measuring nasal bacterial load and its association with otitis media. BMC Ear Nose Throat Disord. 2006. doi: 10.1186/1472-6815-6-10

23. Hyink O, Wescombe PA, Upton M, Ragland N, Burton JP, Tagg JR. Salivaricin $A 2$ and the novel lantibiotic salivaricin B are encoded at adjacent loci on a 190-kilobase transmissible megaplasmid in the oral probiotic strain Streptococcus salivarius K12. Appl Environ Microbiol. 2007;73:1107-13.

24. Heng NCK, Haji-Ishak NS, Kalyan A, Wong AYC, Lovric M, Bridson JM, et al. Genome sequence of the bacteriocin-producing oral probiotic Streptococcus salivarius strain M18. J Bacteriol. 2011;193:6402-3.
25. Wong SS, Toh QZ, Dunne EM, Mulholland EK, Tang ML, Robins-Browne RM, et al. Inhibition of Streptococcus pneumoniae adherence to human epithelial cells in vitro by the probiotic Lactobacillus rhamnosus GG. BMC Res Notes. 2013. doi:10.1186/1756-0500-6-135.

26. Brueggemann AB, Griffiths DT, Meats E, Peto T, Crook DW, Spratt BG. Clonal relationships between invasive and carriage Streptococcus pneumoniae and serotype- and clone-specific differences in invasive disease potential. J Infect Dis. 2003;187:1424-32.

27. Fiedler T, Riani C, Koczan D, Standar K, Kreikemeyer B, Podbielski A. Protective mechanisms of respiratory tract Streptococci against Streptococcus pyogenes biofilm formation and epithelial cell infection. Appl Environ Microbiol. 2013;79:1265-76.

28. Bogaert D, de Groot R, Hermans PWM. Streptococcus pneumoniae colonisation: the key to pneumococcal disease. Lancet Infect Dis. 2004;4:144-54.

29. Nobbs AH, Lamont RJ, Jenkinson HF. Streptococcus adherence and colonization. Microbiol Mol Biol R. 2009;73:407-50.

30. Rydberg C, Mansson A, Uddman R, Riesbeck K, Cardell LO. Toll-like receptor agonists induce inflammation and cell death in a model of head and neck squamous cell carcinomas. Immunology. 2009;128 Suppl 1:e600-11.

31. Guglielmetti S, Taverniti V, Minuzzo M, Arioli S, Stuknyte M, Karp M, et al. Oral bacteria as potential probiotics for the pharyngeal mucosa. Appl Environ Microb. 2010:76:3948-58.

32. Horz HP, Meinelt A, Houben B, Conrads G. Distribution and persistence of probiotic Streptococcus salivarius K12 in the human oral cavity as determined by real-time quantitative polymerase chain reaction. Oral Microbiol Immunol. 2007:22:126-30

33. Power DA, Burton JP, Chilcott CN, Dawes PJ, Tagg JR. Preliminary investigations of the colonisation of upper respiratory tract tissues of infants using a paediatric formulation of the oral probiotic Streptococcus salivarius K12. Euro J Clin Microbiol Infect Dis. 2008;27:1261-63.

34. Burton JP, Cowley S, Simon RR, McKinney J, Wescombe PA, Tagg JR. Evaluation of safety and human tolerance of the oral probiotic Streptococcus salivarius K12: A randomized, placebo-controlled, double-blind study. Food Chem Toxicol. 2011;49:2356-64.

35. Santigati SM, Muscaridola N, Metoldo V, La Mantia I, Stefani S. Colonization, safety, and tolerability study of the Streptococcus salivarius 24SMBC nasal spray for its application in upper respiratory tract infections. J Clin Microbiol Infect Dis. 2015. doi:10.1007/s10096-015-2454-2.

36. Ross KF, Ronson CW, Tagg JR. Isolation and characterization of the lantibiotic salivaricin-A and its structural gene SalA from Streptococcus salivarius 20P3. Appl Environ Microbiol. 1993;59:2014-21.

37. Wescombe PA, Upton M, Renault P, Wirawan RE, Power D, Burton JP, et al. Salivaricin 9, a new lantibiotic produced by Streptococcus salivarius. Microbiology. 2011;157:1290-9.

\section{Submit your next manuscript to BioMed Central and we will help you at every step:}

- We accept pre-submission inquiries

- Our selector tool helps you to find the most relevant journal

- We provide round the clock customer support

- Convenient online submission

- Thorough peer review

- Inclusion in PubMed and all major indexing services

- Maximum visibility for your research

Submit your manuscript at www.biomedcentral.com/submit
) Biomed Central 